Review

\title{
Oncostatin M Modulation of Lipid Storage
}

\section{Carrie M. EIks ${ }^{1}$ and Jacqueline M. Stephens ${ }^{1,2, *}$}

1 Adipocyte Biology Laboratory, Pennington Biomedical Research Center, 6400 Perkins Road, Baton Rouge, LA 70808, USA; E-Mail: carrie.elks@pbrc.edu

2 Department of Biological Sciences, Louisiana State University, 202 Life Sciences Building, Baton Rouge, LA 70803, USA

* Author to whom correspondence should be addressed; E-Mail: jsteph1@1su.edu; Tel.: +1-225-763-2648; Fax: +1-225-578-2597.

Academic Editor: Annette Graham

Received: 21 November 2014 / Accepted: 11 February 2015 / Published: 13 February 2015

\begin{abstract}
Oncostatin M (OSM) is a cytokine belonging to the gp130 family, whose members serve pleiotropic functions. However, several actions of OSM are unique from those of other gp130 cytokines, and these actions may have critical roles in inflammatory mechanisms influencing several metabolic and biological functions of insulin-sensitive tissues. In this review, the actions of OSM in adipose tissue and liver are discussed, with an emphasis on lipid metabolism.
\end{abstract}

Keywords: oncostatin M; gp130 cytokines; adipocyte; obesity; adipose tissue

\section{1. gp130 Cytokines}

The interleukin (IL)-6 family is a group of structurally similar cytokines that includes IL-6, IL-11, IL-27, leukemia inhibitory factor (LIF), oncostatin M (OSM), ciliary neurotrophic factor, cardiotrophin-1 (CT-1), novel neurotrophin-1/B cell stimulating factor-3 or cardiotrophin-like cytokine, and neuropoietin (reviewed in [1]). Since all members of this cytokine family require glycoprotein 130 (gp130) as a common signal transducer in their receptor complexes, the IL-6 family members are referred to as the gp130 cytokines. The principal signal transduction pathway facilitating the response to gp130 cytokines is the Janus Kinase/Signal Transducer and Activator of Transcription (JAK/STAT) pathway, which primarily activates STAT3. 
The gp130 cytokines regulate a diverse array of biological processes, including hematopoiesis, immune responses, inflammation, stem cell potency, cardiovascular pathophysiology, and neuronal survival (reviewed in [2]). Circulating levels of many gp130 cytokines, namely IL-6, CT-1, LIF, and OSM, have been observed in humans [3-9]. Though the actions of this cytokine family in modulating lipid metabolism and fat cell function have not been fully elucidated, some gp130 cytokines, including CNTF and IL-6, have been targeted as potential therapeutic strategies in the treatment of obesity [10]. Some gp130 cytokines can exert profound effects on adipose tissue (AT), body weight, and glucose and lipid metabolism in rodents and humans [11-20]. AT and its primary constituents, adipocytes, are highly responsive to gp130 cytokines [19,21-25]; however, the effects of these cytokines in regulating lipid accumulation have not been fully characterized.

\section{Oncostatin M}

OSM is a gp130 cytokine that shares substantial sequence identity with LIF [26]. LIF and OSM evolved by gene duplication relatively recently [27]. Though originally identified for its ability to inhibit cancer growth in humans [28], OSM can modulate a variety of biological processes. However, unlike other gp130 cytokines, OSM has its own specific receptor, OSMR $\beta$, that heterodimerizes with gp130 [29] and mediates the majority of OSM effects. There is some evidence that OSM is the only gp130 cytokine with the unique ability to signal through two distinct receptor units - the gp130/LIF receptor (LIFR) complex [30] and the gp130/OSMR $\beta$ complex [29]. However, other studies have shown that murine OSM only signals through the gp130/OSMR $\beta$ receptor complex [31,32]. These results have been confirmed, and since there is some receptor cross-talk among gp130 cytokines [33], it is critical to note that that mouse OSM only results in the tyrosine phosphorylation of gp130 and OSMR $\beta$ and does not signal via LIFR [31-33]. Similarly, human OSM only activates gp130 and OSMR $\beta$ and not LIFR in human adipocytes.

OSM can regulate inflammatory responses and is produced by activated $\mathrm{T}$ cells and macrophages [28,34,35]. In murine models of chronic inflammatory diseases, such as rheumatoid arthritis (RA) and multiple sclerosis, OSM has been shown to suppress inflammation [36]. Conversely, elevated OSM expression is found in a variety of inflammatory diseases in humans, including RA and atherosclerosis [37-39]. OSM has important roles in liver development and regeneration [40-42], hepatic insulin resistance and steatosis [43], inflammation [44], and cardiomyocyte dedifferentiation and remodeling [45]. Nevertheless, the actions of OSM on metabolic functions have not been fully elucidated and recent studies suggest pro-inflammatory roles of OSM on adipocytes [46]. Importantly, AT in vivo is highly responsive to OSM as compared to other insulin-sensitive tissues [33]. Mice given acute (20 $\mathrm{min}$ ) OSM injections had robust STAT phosphorylation in two white AT depots (epididymal and retroperitoneal). The response to OSM in brown AT, liver, and skeletal muscle was minimal compared to white AT [33]. It is also known that OSM can inhibit adipocyte differentiation in vitro [25,47]. Several gp130 cytokines can have differential effects on both adipogenesis and insulin-stimulated glucose uptake in vitro and in vivo [19,21-25]. However, the actions of OSM on insulin signaling, lipid metabolism and glucose uptake require further investigation. 


\section{OSM Modulation of Adipocyte Differentiation}

There are many hormones that affect lipid storage by promoting and/or inhibiting adipocyte development (reviewed in [48]). In the recent past, it was speculated that inhibitors of adipocyte development may act as suitable anti-obesity therapeutics by attenuating fat cell mass. In obesity, AT expansion can be accompanied by adipocyte dysfunction and alterations in adipokine secretion that can contribute to the development of metabolic diseases (reviewed in [49]). Cytokines that inhibit adipogenesis, such as tumor necrosis factor alpha and interferon gamma, tend to have metabolically unfavorable effects such as the induction of insulin resistance (reviewed in [50]). These cytokines and other adipocyte differentiation inhibitors can block fat cell expansion, a condition that has been recognized as a causative factor for insulin resistance for over a decade [51].

Several groups have demonstrated that OSM inhibits adipocyte development in vitro [25,33]. Also mice that have a global deletion of OSMR $\beta$ have increased adiposity [52], supporting the notion that OSM acts to block adipogenesis and that lack of OSM signaling leads to increased AT expansion. There is also evidence to suggest that OSM treatment of mice results in weight loss accompanied by decreased fat mass and, therefore, less lipid accumulation [52,53]. However, the OSM doses used in these studies were very high (12.5 ng/g body weight, administered twice daily) [52,53] and may have caused illness in the animals. In humans with diseases such as cancer and periodontitis, OSM is present in circulation at values ranging from $20 \mathrm{pg} / \mathrm{mL}$ to $100 \mathrm{pg} / \mathrm{mL}$ [54,55], while OSM is minimally detectable in healthy individuals. Therefore, the doses used in these animal studies are at least three to four orders of magnitude above the highest reported circulating OSM value for a human, and the impact of these high doses is likely much greater in mice. Nonetheless, these independent studies strongly suggest that OSM inhibits adipocyte development both in vitro and in vivo.

\section{OSM is an Adipokine}

An important AT function includes the production and secretion of factors (adipokines) that mediate whole body metabolism. Several adipokines can modulate physiological systems, as well as pathological conditions such as insulin resistance and inflammation (reviewed in [56]). AT is a well-known source of two gp130 cytokines, IL-6 [57,58] and CT-1 [7]. Previous studies have shown that murine adipocytes in vitro and white AT in vivo are responsive to OSM [33]. Hence, we examined OSM expression in mouse and human AT. We demonstrated that OSM mRNA and protein levels were elevated in AT of both $o b / o b$ mice and high-fat diet (HFD)-fed B6 mice [46]; these rodent models are both used to study obesity and type 2 diabetes (T2DM). An analysis of human subcutaneous AT revealed that OSM levels correlated with body mass index (BMI), with substantial inductions of OSM protein levels seen in AT from subjects with BMIs of 40 or above [46]. These were the first studies to demonstrate that OSM mRNA and protein levels are elevated in obese/T2DM mice and humans. Interestingly, OSM is present in non-adipocyte cells of human AT. In mice, OSM is present in both CD11c+ and CD11c- macrophages that are $\mathrm{F} 4 / 80+$ and are found in AT of wild type and $o b / o b$ mice [46]. OSMR $\beta$ is highly expressed in adipocytes, and OSM treatment of adipocytes induces IL-6 and PAI-1 expression [46,59]. In addition to positively correlating with body weight, increased OSM levels also positively correlate with insulin levels and are negatively associated with glucose disposal rates in humans [46]. Collectively, our data suggest that AT-derived OSM acts on preadipocytes and adipocytes (see Figure 1) and may modulate glucose and lipid metabolism and contribute to metabolic disease states. 


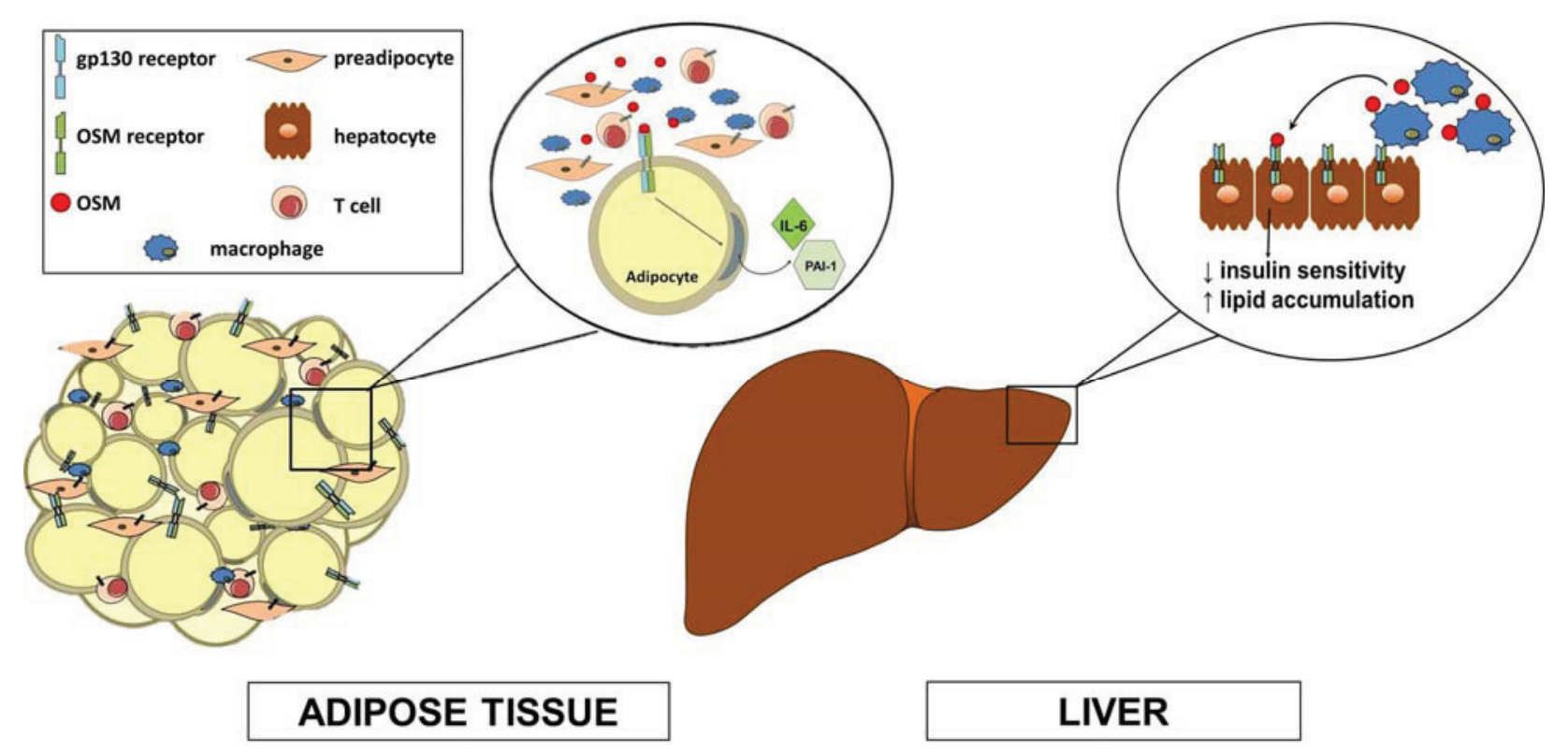

Figure 1. Oncostatin M (OSM) is produced in adipose tissue and liver immune cells and acts in a paracrine manner in these insulin-sensitive tissues. OSM is produced in T cells and macrophages that are found in adipose tissue and are elevated in conditions of obesity/insulin resistance. OSM receptors are present on preadipocytes and adipocytes, but not macrophages. It is well-known that OSM inhibits adipocyte differentiation. In addition, OSM acts on adipocytes to induce IL-6 and PAI-1 production. These abilities of OSM suggest that blocking OSM receptor activity in preadipocytes and adipocytes may be metabolically beneficial. In liver, OSM is produced in Kupffer cells (resident macrophages) and acts in a paracrine manner on hepatocytes to decrease insulin sensitivity and increase liver lipid accumulation.

\section{Hepatic Effects of OSM}

The hepatic functions of OSM are diverse and well documented [40-43,60-64]. A few years after the discovery of human OSM, its role as a potent inducer of the acute phase response in rat primary hepatocytes was identified [64]. Similar effects of mouse OSM were subsequently reported [65]. Evidence also suggests that hepcidin, a protein produced by the liver and a key regulator of iron metabolism, is an OSM target [60] and that OSM may play a role in anemia-associated disorders [60,62]. Interestingly, critical roles for OSM in fetal hepatic cell differentiation and hematopoiesis have also been reported [42]. Liver regeneration capability is impaired in OSMR $\beta$ knockout mice [41], and OSM has been shown to stimulate rat oval cell differentiation into hepatocytes, suggesting a role for OSM in the regenerative ability of hepatic tissue [63].

Further, OSM was found to up regulate the LDL receptor and rapidly increase phospholipid and diacylglycerol metabolism in HepG2 cells, highlighting a possible role for OSM in hepatic lipid metabolism [61]. Further support of this potential role is demonstrated in Kupffer cells, whose OSM production can inhibit the expression of several key enzymes of hepatic lipid metabolism [43]. Kupffer cell OSM has also been shown to attenuate insulin-stimulated Akt phosphorylation and glucokinase induction in hepatocytes, and is also up regulated in non-alcoholic steatohepatitis [43]. These results suggest overall that OSM produced by Kupffer cells may have a paracrine effect on hepatocytes to cause 
insulin resistance and lipid accumulation, and that these effects may contribute to systemic insulin resistance and metabolic syndrome. These results are consistent with observations of OSM being produced in AT macrophages (ATMs) and modulating pro-inflammatory genes in adipocytes (see Figure 1).

\section{Metabolic Studies in OSMRß Knockout Mice}

Two recent studies from Komori and colleagues in OSMR $\beta$-deficient mice suggest a metabolically protective role for OSM signaling [52,53]. However, it is necessary to interpret these studies with caution, as they were conducted in global OSMR $\beta$ KO mice. Since OSMR $\beta$ plays a known role in hematopoiesis and other biological functions beginning prior to birth [42], it is possible that many of the effects seen in these studies were due to other developmental and/or systemic alterations.

Results from the first study indicate that OSMR $\beta$ KO mice exhibit AT inflammation, insulin resistance, increased hepatic and serum lipid concentrations, and beta cell hyperplasia on normal chow diet [52]. These results suggest that OSM signaling plays an important role in lipid handling in AT and liver. Also, wild-type B6 mice were injected with OSM twice daily for one week and glucose tolerance, insulin sensitivity, and ATM populations assessed. OSM treatment decreased the total number of F4/80+ cells, but the percentage of pro-inflammatory M1 ATMs was lower while the percentage of anti-inflammatory M2 ATMs increased [52]. Improvements in glucose tolerance and insulin sensitivity in OSM-treated mice were also observed, suggesting that possible metabolically favorable improvements likely have beneficial effects on lipid metabolism. However, it is difficult to assess whether the mice were healthy during the injections, as no food intake or body weight data were reported [52]. Possible decreases in appetite and body weight, resulting from the supraphysiological doses of OSM used in these experiments, could account for the alterations observed in glucose metabolism.

In a follow-up study by the same group, $o b / o b$ mice were injected with OSM twice daily for one week [53]. Significant improvements in insulin sensitivity, glucose tolerance, AT inflammation, and hepatic steatosis were seen in OSM-injected mice. However, body weight also significantly decreased in the OSM-injected mice, and this may partially account for the improvements. Additionally, OSMR $\beta$ KO mice were fed a HFD for 8 weeks and exhibited greater body weight and food intake than control mice. Further, the insulin resistance, AT inflammation, and hepatic steatosis observed were more severe in the obese $\mathrm{KO}$ mice than in the control mice [53]. The severity of these effects was not resolved when OSMR $\beta$ KO mice were pair-fed with control mice, suggesting that the effects were independent of body weight gain. AT inflammation, ATM accumulation, and ATM polarization to the M1 phenotype was markedly increased in KO mice as early as 2 weeks on HFD. Hepatic lipid metabolism was more closely evaluated in this study, and OSMR $\beta$ KO mice demonstrated more severe liver lipid accumulation as determined by histology, tissue triglyceride quantification, and tissue total cholesterol quantification [53]. The OSMR $\beta$ KO mice also exhibited increased hepatic expression of fatty acid synthesis genes, which was not affected by pair feeding. These results suggest that altered lipid metabolism in the OSMR $\beta$ KO mice may be responsible, in part, for the insulin resistance reported in these animals.

While the results from both studies do support a putative role for OSM signaling in lipid metabolism in both AT and liver, the use of global OSMR $\beta$ KO mice makes it difficult to determine cause and effect and to assess whether their phenotype is related to developmental factors. Future studies should be conducted on tissue-specific or tissue-specific inducible OSMR $\beta$ KO mice to address current confounding data and the developmental and systemic effects of OSM. 


\section{Summary and Future Directions}

Our understanding of OSM and its ability to modulate lipid metabolism is rudimentary. To date, there is confounding data on whether OSM induces metabolically beneficial [52,53] or metabolically detrimental effects $[43,46,66]$. Since OSM is highly produced in conditions of excess lipid storage as judged by adiposity [46], we predict that OSM will have profound effects on glucose and lipid metabolism (see Figure 1). As indicated above, it will be essential to examine tissue-specific manipulation of both OSM and OSMR $\beta$ to determine the primary tissue sources of OSM as well as the action of this cytokine on tissues involved in lipid metabolism.

\section{Acknowledgments}

Work supported by grant R01DK052968-15 from the NIH (to Jacqueline M. Stephens).

\section{Conflicts of Interest}

The authors declare no conflict of interest.

\section{References}

1. Fasnacht, N.; Muller, W. Conditional gp130 deficient mouse mutants. Semin. Cell Dev. Biol. 2008, 19, 379-384.

2. Heinrich, P.C.; Behrmann, I.; Haan, S.; Hermanns, H.M.; Muller-Newen, G.; Schaper, F. Principles of interleukin (IL)-6-type cytokine signalling and its regulation. Biochem. J. 2003, 374, 1-20.

3. Celik, A.; Sahin, S.; Koc, F.; Karayakali, M.; Sahin, M.; Benli, I.; Kadi, H.; Burucu, T.; Ceyhan, K.; Erkorkmaz, U.; et al. Cardiotrophin-1 plasma levels are increased in patients with diastolic heart failure. Med. Sci. Monit. 2012, 18, CR25-CR31.

4. Hansen, D.; Dendale, P.; Beelen, M.; Jonkers, R.A.; Mullens, A.; Corluy, L.; Meeusen, R.; van Loon, L.J. Plasma adipokine and inflammatory marker concentrations are altered in obese, as opposed to non-obese, type 2 diabetes patients. Eur. J. Appl. Physiol. 2010, 109, 397-404.

5. Kern, P.A.; Ranganathan, S.; Li, C.; Wood, L.; Ranganathan, G. Adipose tissue tumor necrosis factor and interleukin-6 expression in human obesity and insulin resistance. Am. J. Physiol. Endocrinol. Metab. 2001, 280, E745-E751.

6. Lopez, B.; Gonzalez, A.; Querejeta, R.; Barba, J.; Diez, J. Association of plasma cardiotrophin-1 with stage $\mathrm{C}$ heart failure in hypertensive patients: Potential diagnostic implications. J. hypertens. 2009, 27, 418-424.

7. Natal, C.; Fortuno, M.A.; Restituto, P.; Bazan, A.; Colina, I.; Diez, J.; Varo, N. Cardiotrophin-1 is expressed in adipose tissue and upregulated in the metabolic syndrome. Am. J. Physiol. Endocrinol. Metab. 2008, 294, E52-E60.

8. Pradeep, A.R.; S, T.M.; Garima, G.; Raju, A. Serum levels of oncostatin M (a gp 130 cytokine): An inflammatory biomarker in periodontal disease. Biomarkers 2010, 15, 277-282. 
9. Slevin, M.; Krupinski, J.; Mitsios, N.; Perikleous, C.; Cuadrado, E.; Montaner, J.; Sanfeliu, C.; Luque, A.; Kumar, S.; Kumar, P.; et al. Leukaemia inhibitory factor is over-expressed by ischaemic brain tissue concomitant with reduced plasma expression following acute stroke. Eur. J. Neurol. 2008, 15, 29-37.

10. Febbraio, M.A. Gp130 receptor ligands as potential therapeutic targets for obesity. J. Clin. Investig. 2007, 117, 841-849.

11. Wallenius, V.; Wallenius, K.; Ahren, B.; Rudling, M.; Carlsten, H.; Dickson, S.L.; Ohlsson, C.; Jansson, J.O. Interleukin-6-deficient mice develop mature-onset obesity. Nat. Med. 2002, 8, 75-79.

12. Di Gregorio, G.B.; Hensley, L.; Lu, T.; Ranganathan, G.; Kern, P.A. Lipid and carbohydrate metabolism in mice with a targeted mutation in the IL-6 gene: Absence of development of age-related obesity. Am. J. Physiol. Endocrinol. Metab. 2004, 287, E182-E187.

13. Rotter, V.; Nagaev, I.; Smith, U. Interleukin-6 (IL-6) induces insulin resistance in 3t3-11 adipocytes and is, like IL-8 and tumor necrosis factor-alpha, overexpressed in human fat cells from insulin-resistant subjects. J. Biol. Chem. 2003, 278, 45777-45784.

14. Gloaguen, I.; Costa, P.; Demartis, A.; Lazzaro, D.; di Marco, A.; Graziani, R.; Paonessa, G.; Chen, F.; Rosenblum, C.I.; van der Ploeg, L.H.; et al. Ciliary neurotrophic factor corrects obesity and diabetes associated with leptin deficiency and resistance. Proc. Natl. Acad. Sci. USA 1997, 94, 6456-6461.

15. Lambert, P.D.; Anderson, K.D.; Sleeman, M.W.; Wong, V.; Tan, J.; Hijarunguru, A.; Corcoran, T.L.; Murray, J.D.; Thabet, K.E.; Yancopoulos, G.D.; et al. Ciliary neurotrophic factor activates leptin-like pathways and reduces body fat, without cachexia or rebound weight gain, even in leptin-resistant obesity. Proc. Natl. Acad. Sci. USA 2001, 98, 4652-4657.

16. Sleeman, M.W.; Garcia, K.; Liu, R.; Murray, J.D.; Malinova, L.; Moncrieffe, M.; Yancopoulos, G.D.; Wiegand, S.J. Ciliary neurotrophic factor improves diabetic parameters and hepatic steatosis and increases basal metabolic rate in $\mathrm{db} / \mathrm{db}$ mice. Proc. Natl. Acad. Sci. USA 2003, 100, 14297-14302.

17. Ettinger, M.P.; Littlejohn, T.W.; Schwartz, S.L.; Weiss, S.R.; McIlwain, H.H.; Heymsfield, S.B.; Bray, G.A.; Roberts, W.G.; Heyman, E.R.; Stambler, N.; et al. Recombinant variant of ciliary neurotrophic factor for weight loss in obese adults: A randomized, dose-ranging study. JAMA 2003, 289, 1826-1832.

18. Bluher, S.; Moschos, S.; Bullen, J., Jr.; Kokkotou, E.; Maratos-Flier, E.; Wiegand, S.J.; Sleeman, M.W.; Mantzoros, C.S. Ciliary neurotrophic factor ax15 alters energy homeostasis, decreases body weight, and improves metabolic control in diet-induced obese and ucp1-dta mice. Diabetes 2004, 53, 2787-2796.

19. Zvonic, S.; Cornelius, P.; Stewart, W.C.; Mynatt, R.L.; Stephens, J.M. The regulation and activation of ciliary neurotrophic factor signaling proteins in adipocytes. J. Biol. Chem. 2003, 278, 2228-2235.

20. Crowe, S.; Turpin, S.M.; Ke, F.; Kemp, B.E.; Watt, M.J. Metabolic remodeling in adipocytes promotes ciliary neurotrophic factor-mediated fat loss in obesity. Endocrinology 2008, 149, 2546-2556.

21. Balhoff, J.P.; Stephens, J.M. Highly specific and quantitative activation of stats in 3t3-11 adipocytes. Biochem. Biophys. Res. Commun. 1998, 247, 894-900.

22. Tenney, R.; Stansfield, K.; Pekala, P.H. Interleukin 11 signaling in 3t3-11 adipocytes. J. Cell. Physiol. 2005, 202, 160-166. 
23. Stephens, J.M.; Lumpkin, S.J.; Fishman, J.B. Activation of signal transducers and activators of transcription 1 and 3 by leukemia inhibitory factor, oncostatin-m, and interferon-gamma in adipocytes. J. Biol. Chem. 1998, 273, 31408-31416.

24. Zvonic, S.; Hogan, J.C.; Arbour-Reily, P.; Mynatt, R.L.; Stephens, J.M. Effects of cardiotrophin on adipocytes. J. Biol. Chem. 2004, 279, 47572-47579.

25. White, U.A.; Stewart, W.C.; Mynatt, R.L.; Stephens, J.M. Neuropoietin attenuates adipogenesis and induces insulin resistance in adipocytes. J. Biol. Chem. 2008, 283, 22505-22512.

26. Rose, T.M.; Lagrou, M.J.; Fransson, I.; Werelius, B.; Delattre, O.; Thomas, G.; de Jong, P.J.; Todaro, G.J.; Dumanski, J.P. The genes for oncostatin M (OSM) and leukemia inhibitory factor (LIF) are tightly linked on human chromosome 22. Genomics 1993, 17, 136-140.

27. Rose, T.M.; Bruce, A.G. Oncostatin $\mathrm{M}$ is a member of a cytokine family that includes leukemia-inhibitory factor, granulocyte colony-stimulating factor, and interleukin 6. Proc. Natl. Acad. Sci. USA 1991, 88, 8641-8645.

28. Zarling, J.M.; Shoyab, M.; Marquardt, H.; Hanson, M.B.; Lioubin, M.N.; Todaro, G.J. Oncostatin M: A growth regulator produced by differentiated histiocytic lymphoma cells. Proc. Natl. Acad. Sci. USA 1986, 83, 9739-9743.

29. Mosley, B.; de Imus, C.; Friend, D.; Boiani, N.; Thoma, B.; Park, L.S.; Cosman, D. Dual oncostatin M (OSM) receptors. Cloning and characterization of an alternative signaling subunit conferring OSM-specific receptor activation. J. Biol. Chem. 1996, 271, 32635-32643.

30. Gearing, D.P.; Comeau, M.R.; Friend, D.J.; Gimpel, S.D.; Thut, C.J.; McGourty, J.; Brasher, K.K.; King, J.A.; Gillis, S.; Mosley, B.; et al. The IL-6 signal transducer, gp130: An oncostatin M receptor and affinity converter for the lif receptor. Science 1992, 255, 1434-1437.

31. Ichihara, M.; Hara, T.; Kim, H.; Murate, T.; Miyajima, A. Oncostatin M and leukemia inhibitory factor do not use the same functional receptor in mice. Blood 1997, 90, 165-173.

32. Lindberg, R.A.; Juan, T.S.; Welcher, A.A.; Sun, Y.; Cupples, R.; Guthrie, B.; Fletcher, F.A. Cloning and characterization of a specific receptor for mouse oncostatin M. Mol. Cell. Biol. 1998, 18, 3357-3367.

33. White, U.A.; Stewart, W.C.; Stephens, J.M. Gp130 cytokines exert differential patterns of crosstalk in adipocytes both in vitro and in vivo. Obesity (Silver Spring) 2011, 19, 903-910.

34. Brown, T.J.; Lioubin, M.N.; Marquardt, H. Purification and characterization of cytostatic lymphokines produced by activated human T lymphocytes. Synergistic antiproliferative activity of transforming growth factor beta 1, interferon-gamma, and oncostatin $\mathrm{M}$ for human melanoma cells. J. Immunol. 1987, 139, 2977-2983.

35. Suda, T.; Chida, K.; Todate, A.; Ide, K.; Asada, K.; Nakamura, Y.; Suzuki, K.; Kuwata, H.; Nakamura, H. Oncostatin M production by human dendritic cells in response to bacterial products. Cytokine 2002, 17, 335-340.

36. Wahl, A.F.; Wallace, P.M. Oncostatin M in the anti-inflammatory response. Ann. Rheum. Dis. 2001, 60, Siii75-Siii80.

37. Hui, W.; Bell, M.; Carroll, G. Detection of oncostatin M in synovial fluid from patients with rheumatoid arthritis. Ann. Rheum. Dis. 1997, 56, 184-187. 
38. Albasanz-Puig, A.; Murray, J.; Preusch, M.; Coan, D.; Namekata, M.; Patel, Y.; Dong, Z.M.; Rosenfeld, M.E.; Wijelath, E.S. Oncostatin M is expressed in atherosclerotic lesions: A role for oncostatin M in the pathogenesis of atherosclerosis. Atherosclerosis 2011, 216, 292-298.

39. Demyanets, S.; Kaun, C.; Rychli, K.; Pfaffenberger, S.; Kastl, S.P.; Hohensinner, P.J.; Rega, G.; Katsaros, K.M.; Afonyushkin, T.; Bochkov, V.N.; et al. Oncostatin M-enhanced vascular endothelial growth factor expression in human vascular smooth muscle cells involves pi3k-, p38 mapk-, erk1/2and stat1/stat3-dependent pathways and is attenuated by interferon- $\gamma$. Basic Res. Cardiol. 2011, 106, 217-231.

40. Kamiya, A.; Kinoshita, T.; Ito, Y.; Matsui, T.; Morikawa, Y.; Senba, E.; Nakashima, K.; Taga, T.; Yoshida, K.; Kishimoto, T.; et al. Fetal liver development requires a paracrine action of oncostatin M through the gp130 signal transducer. EMBO J. 1999, 18, 2127-2136.

41. Nakamura, K.; Nonaka, H.; Saito, H.; Tanaka, M.; Miyajima, A. Hepatocyte proliferation and tissue remodeling is impaired after liver injury in oncostatin M receptor knockout mice. Hepatology 2004, 39, 635-644.

42. Miyajima, A.; Kinoshita, T.; Tanaka, M.; Kamiya, A.; Mukouyama, Y.; Hara, T. Role of oncostatin M in hematopoiesis and liver development. Cytokine Growth Factor Rev. 2000, 11, 177-183.

43. Henkel, J.; Gartner, D.; Dorn, C.; Hellerbrand, C.; Schanze, N.; Elz, S.R.; Puschel, G.P. Oncostatin M produced in kupffer cells in response to pge2: Possible contributor to hepatic insulin resistance and steatosis. Lab. Investig. 2011, 91, 1107-1117.

44. Wallace, P.M.; MacMaster, J.F.; Rouleau, K.A.; Brown, T.J.; Loy, J.K.; Donaldson, K.L.; Wahl, A.F. Regulation of inflammatory responses by oncostatin M. J. Immunol. 1999, 162, 5547-5555.

45. Kubin, T.; Poling, J.; Kostin, S.; Gajawada, P.; Hein, S.; Rees, W.; Wietelmann, A.; Tanaka, M.; Lorchner, H.; Schimanski, S.; et al. Oncostatin M is a major mediator of cardiomyocyte dedifferentiation and remodeling. Cell Stem Cell 2011, 9, 420-432.

46. Sanchez-Infantes, D.; White, U.A.; Elks, C.M.; Morrison, R.F.; Gimble, J.M.; Considine, R.V.; Ferrante, A.W.; Ravussin, E.; Stephens, J.M. Oncostatin M is produced in adipose tissue and is regulated in conditions of obesity and type 2 diabetes. J. Clin. Endocriol. Metab. 2014, 99, E217-E225.

47. Miyaoka, Y.; Tanaka, M.; Naiki, T.; Miyajima, A. Oncostatin M inhibits adipogenesis through the ras/erk and STAT5 signaling pathways. J. Biol. Chem. 2006, 281, 37913-37920.

48. Sarjeant, K.; Stephens, J.M. Adipogenesis. Cold Spring Harb. Perspect. Biol. 2012, 4, a008417.

49. Bluher, M. Clinical relevance of adipokines. Diabetes Metab. J. 2012, 36, 317-327.

50. Ouchi, N.; Parker, J.L.; Lugus, J.J.; Walsh, K. Adipokines in inflammation and metabolic disease. Nat. Rev. Immunol. 2011, 11, 85-97.

51. Danforth, E. Failure of adipocyte differentiation causes type ii diabetes mellitus? Nat. Genet. 2000, $26,13-13$.

52. Komori, T.; Tanaka, M.; Senba, E.; Miyajima, A.; Morikawa, Y. Lack of oncostatin M receptor $\beta$ leads to adipose tissue inflammation and insulin resistance by switching macrophage phenotype. J. Biol. Chem. 2013, 288, 21861-21875.

53. Komori, T.; Tanaka, M.; Senba, E.; Miyajima, A.; Morikawa, Y. Deficiency of oncostatin M receptor $\beta$ (OSMR $\beta$ ) exacerbates high-fat diet-induced obesity and related metabolic disorders in mice. J. Biol. Chem. 2014, 289, 13821-13837. 
54. Liang, H.; Block, T.M.; Wang, M.; Nefsky, B.; Long, R.; Hafner, J.; Mehta, A.S.; Marrero, J.; Gish, R.; Norton, P.A.; et al. Interleukin-6 and oncostatin $\mathrm{M}$ are elevated in liver disease in conjunction with candidate hepatocellular carcinoma biomarker gp73. Cancer Biomark. 2012, 11, 161-171.

55. Thorat, M.; Ar, P.; Garg, G. Correlation of levels of oncostatin M cytokine in crevicular fluid and serum in periodontal disease. Int. J. Oral Sci. 2010, 2, 198-207.

56. Lehr, S.; Hartwig, S.; Sell, H. Adipokines: A treasure trove for the discovery of biomarkers for metabolic disorders. Proteomics. Clin. Appl. 2012, 6, 91-101.

57. Mohamed-Ali, V.; Goodrick, S.; Rawesh, A.; Katz, D.R.; Miles, J.M.; Yudkin, J.S.; Klein, S.; Coppack, S.W. Subcutaneous adipose tissue releases interleukin-6, but not tumor necrosis factor-alpha, in vivo. J. Clin. Endocrinol. Metab. 1997, 82, 4196-4200.

58. Fried, S.K.; Bunkin, D.A.; Greenberg, A.S. Omental and subcutaneous adipose tissues of obese subjects release interleukin-6: Depot difference and regulation by glucocorticoid. J. Clin. Endocrinol. Metab. 1998, 83, 847-850.

59. Rega, G.; Kaun, C.; Weiss, T.W.; Demyanets, S.; Zorn, G.; Kastl, S.P.; Steiner, S.; Seidinger, D.; Kopp, C.W.; Frey, M.; et al. Inflammatory cytokines interleukin-6 and oncostatin M induce plasminogen activator inhibitor-1 in human adipose tissue. Circulation 2005, 111, 1938-1945.

60. Chung, B.; Verdier, F.; Matak, P.; Deschemin, J.-C.; Mayeux, P.; Vaulont, S. Oncostatin M is a potent inducer of hepcidin, the iron regulatory hormone. FASEB J. 2010, 24, 2093-2103.

61. Grove, R.I.; Mazzucco, C.E.; Radka, S.F.; Shoyab, M.; Kiener, P.A. Oncostatin M up-regulates low density lipoprotein receptors in hepg2 cells by a novel mechanism. J. Biol. Chem. 1991, 266, 18194-18199.

62. Kanda, J.; Uchiyama, T.; Tomosugi, N.; Higuchi, M.; Uchiyama, T.; Kawabata, H. Oncostatin M and leukemia inhibitory factor increase hepcidin expression in hepatoma cell lines. Int. J. Hematol. 2009, 90, 545-552.

63. Okaya, A.; Kitanaka, J.; Kitanaka, N.; Satake, M.; Kim, Y.; Terada, K.; Sugiyama, T.; Takemura, M.; Fujimoto, J.; Terada, N.; et al. Oncostatin M inhibits proliferation of rat oval cells, oc15-5, inducing differentiation into hepatocytes. Am. J. Pathol. 2005, 166, 709-719.

64. Richards, C.D.; Brown, T.J.; Shoyab, M.; Baumann, H.; Gauldie, J. Recombinant oncostatin M stimulates the production of acute phase proteins in hepg2 cells and rat primary hepatocytes in vitro. J. Immunol. 1992, 148, 1731-1736.

65. Richards, C.D.; Kerr, C.; Tanaka, M.; Hara, T.; Miyajima, A.; Pennica, D.; Botelho, F.; Langdon, C.M. Regulation of tissue inhibitor of metalloproteinase-1 in fibroblasts and acute phase proteins in hepatocytes in vitro by mouse oncostatin M, cardiotrophin-1, and il-6. J. Immunol. 1997, 159, 2431-2437.

66. Song, H.Y.; Kim, M.R.; Lee, M.J.; Jeon, E.S.; Bae, Y.C.; Jung, J.S.; Kim, J.H. Oncostatin M decreases adiponectin expression and induces dedifferentiation of adipocytes by jak3- and mek-dependent pathways. Int. J. Biochem. Cell Biol. 2007, 39, 439-449.

(C) 2015 by the authors; licensee MDPI, Basel, Switzerland. This article is an open access article distributed under the terms and conditions of the Creative Commons Attribution license (http://creativecommons.org/licenses/by/4.0/). 